Published in final edited form as:

Environ Res. 2020 January ; 180: 108841. doi:10.1016/j.envres.2019.108841.

\title{
Short-term Exposures to Particulate Matter Gamma Radiation Activities and Biomarkers of Systemic Inflammation and Endothelial Activation in COPD Patients
}

\author{
Shaodan Huang ${ }^{1,{ }^{*},}$ Eric Garshick ${ }^{2,3}$, Carolina L.Z. Vieira ${ }^{1}$, Stephanie T. Grady ${ }^{3,4}$, Joel D. \\ Schwartz $^{1,3,5}$, Brent A. Coull ${ }^{1,6}$, Jaime E. Hart ${ }^{1,3}$, Francine Laden ${ }^{1,3,5}$, Petros Koutrakis ${ }^{1}$ \\ ${ }^{1}$ Department of Environmental Health, Harvard T.H. Chan School of Public Health, Boston, MA, \\ USA \\ 2Pulmonary, Allergy, Sleep, and Critical Care Medicine Section, Medical Service, VA Boston \\ Healthcare System, Boston, MA, USA \\ ${ }^{3}$ Channing Division of Network Medicine, Department of Medicine, Brigham and Women's \\ Hospital and Harvard Medical School, Boston, MA, USA \\ ${ }^{4}$ Research and Development Service, VA Boston Healthcare System, Boston, MA, USA \\ ${ }^{5}$ Department of Epidemiology, Harvard T.H. Chan School of Public Health, Boston, MA, USA \\ ${ }^{6}$ Department of Biostatistics, Harvard T.H. Chan School of Public Health, Boston, MA, USA
}

\section{Abstract}

Background: We hypothesized that particulate matter (PM) gamma activity (gamma radiation associated with PM) is associated with systemic effects.

Objective: Examine short-term relationships between ambient and indoor exposures to PM gamma activities with systemic inflammation and endothelial activation in chronic obstructive pulmonary disease (COPD) patients.

Methods: In 85 COPD patients from Eastern Massachusetts, USA from 2012-2014, plasma Creactive protein (CRP), interleukin-6 (IL-6), and soluble vascular cell adhesion molecule-1 (sVCAM-1) were measured seasonally up to four times. We used US EPA RadNet data measuring ambient gamma radiation attached to PM adjusted for background radiation, and estimated inhome gamma radiation exposures using the ratio of in-home-to-ambient sulfur in $\mathrm{PM}_{2.5}$. Linear mixed-effects regression models were used to determine associations between moving averages of

*Corresponding author. shhuang@hsph.harvard.edu; Tel.: +1 (617) 480-6288; Fax: +1 (617) 488-2335.

Publisher's Disclaimer: This is a PDF file of an unedited manuscript that has been accepted for publication. As a service to our customers we are providing this early version of the manuscript. The manuscript will undergo copyediting, typesetting, and review of the resulting proof before it is published in its final form. Please note that during the production process errors may be discovered which could affect the content, and all legal disclaimers that apply to the journal pertain.

Competing financial interests: The authors do not have any competing financial interests, including relevant financial interests, activities, relationships, and affiliations.

Declaration of interests

The authors declare that they have no known competing financial interests or personal relationships that could have appeared to influence the work reported in this paper. 
PM gamma activities through the week before phlebotomy with these biomarkers. We explored ambient and indoor $\mathrm{PM}_{2.5}$, black carbon (BC), and $\mathrm{NO}_{2}$ as confounders.

Results: Ambient and indoor PM gamma activities measured as energy spectra classes 3 through 9 were positively associated with CRP and IL-6. For example, averaged from phlebotomy day through previous 6 days, each IQR increase in indoor PM gamma activity for each spectra class, was associated with an CRP increase ranging from $7.45 \%$ (95\%CI: $2.77,12.4)$ to $13.4 \%$ (95\%CI: $5.82,21.4)$ and for ambient exposures were associated with an increase of $8.75 \%$ (95\%CI: -0.57 , $18.95)$ to $14.8 \%$ (95\%CI: $4.5,26.0)$. Indoor exposures were associated with IL-6 increase of $3.56 \%$ (95\% CI: $0.31,6.91)$ to $6.46 \%(95 \% \mathrm{CI}: 1.33,11.85)$ and ambient exposures were associated with an increase of $0.03 \%(95 \% \mathrm{CI}:-6.37,6.87)$ to $3.50 \%$ (95\% CI: $-3.15,10.61)$. There were no positive associations with sVCAM-1. Sensitivity analyses using two-pollutant models showed similar effects.

Conclusions: Our results demonstrate that short-term exposures to environmental PM gamma radiation activities were associated with systemic inflammation in COPD patients.

\section{Keywords}

gamma radiation; particulate matter (PM); particulate matter gamma radiation activities; systemic inflammatory biomarkers; chronic obstructive pulmonary disease (COPD)

\section{Introduction}

Chronic obstructive pulmonary disease (COPD) is a progressive and debilitating chronic disease that affects more than 15.7 million people in the United States and was the fourth leading cause of death in the United States in 2016 (Croft et al., 2018; Wheaton et al., 2015). Biomarkers of systemic inflammation are elevated in COPD patients and associated with more severe disease and increased mortality (Agusti, 2005; Agusti et al., 2003; Agusti et al., 2012; Mackay et al., 2016; Shaw et al., 2014; Su et al., 2016). Exposure to air pollution has be linked to increased levels of systemic inflammation (Jiang et al., 2016), especially in COPD patients who may also be more vulnerable to the detrimental effects of air pollutants (Garshick, 2014; Garshick, 2018; Heinrich and Schikowski, 2018).

In addition to air pollution, humans are exposed to ionizing radiation, including alpha, beta, and gamma radiation from the decay of radionuclides (EPA, 1972). Ionizing radiation can disrupt chemical bonds in the structural components of cells, damage molecules, and induce DNA strand breaks (Henner et al., 1982; Foray et al., 1999; Mishra, 2004). The largest sources of ionizing radiation are natural terrestrial and extra-terrestrial radiation sources (e.g., the decay of progenies of uranium-238, thorium- 232 and potassium-40 in earth's crust and products of galactic cosmic rays) (EPA, 1972; Shahbazi-Gahrouei et al., 2013).

Inhalation of particulate matter (PM) radioactivity is an important route of ionizing radiation exposure (Karam, 2004). Alpha radiation, which is more damaging compared to other types of ionizing radiation (beta and gamma radiation), cannot penetrate the epidermis. Therefore, exposure to alpha radiation may occur through internal exposure (inhalation or ingestion). Environmental radioactive nuclei from background sources (natural terrestrial and extraterrestrial) can attach to respirable PM (Mohamed et al., 2014; Porstendörfer, 1994 and 
2001). Once inhaled, PM with attached radioactive nuclei deposit on the respiratory tract and can translocate into systemic circulation (Marsh and Bailey, 2013). As the emission of alpha or beta radiation is frequently accompanied by the emission of gamma activities, PM gamma activities can be considered as surrogates of total radioactivity including alpha and beta activities (Stacey, 2007). We previously reported associations between increases in PM gamma activities and a reduction in forced expiratory volume in 1 second $\left(\mathrm{FEV}_{1}\right)$ and forced vital capacity (FVC) (Vieira et al., 2019). However, up to our best knowledge, there is no study about the effects of PM gamma activities on systemic inflammation or vascular endothelial activation biomarkers, which may contribute to the development of both pulmonary and systemic endothelial dysfunction, in COPD patients (Polverino et al., 2018).

The objective of this research is to investigate the systemic effects of PM radioactivity in COPD patients. We explored relationships between ambient PM gamma activities (surrogates of ambient PM radioactivity) and the indoor infiltration of ambient PM radioactivity on plasma biomarkers of systemic inflammation (IL-6 and CRP) and vascular endothelial activation (sVCAM-1) in COPD patients from Eastern Massachusetts, USA.

\section{Methods}

\subsection{Population}

This study is part of the COPD and Air Pollution Study (CAPS), where we previously reported exposure-response relationships between indoor black carbon (BC) and biomarkers of systemic inflammation (Garshick et al., 2018). We recruited 85 COPD patients from Eastern Massachusetts between October 2012 and December 2014 as previously described (Garshick et al., 2018). Eligibility was confirmed at an in-person visit that included pre- and post-bronchodilator spirometry. The inclusion criteria were: individuals age 40 or greater, former smokers with at least 10 pack years of smoking, and post bronchodilator spirometry with $\mathrm{FEV}_{1} / \mathrm{FVC}<0.70$ or emphysema on clinical CT scan reports. Persons with malignancies other than local skin or stable prostate cancer, systemic inflammatory disease such as rheumatoid arthritis, and indoor sources of combustion-related PM including smoking, wood stove burning, fireplace use, and candle or incense burning were excluded. Each participant returned for 1-4 additional seasonal visits, where they completed questionnaires, provided blood and urine samples, and performed spirometry. Visits were scheduled a minimum of two weeks after completion of antibiotics or steroids for a COPD exacerbation. The study protocol was approved by the Institutional Review Boards of VA Boston and Harvard Medical School, and written informed consent was obtained.

\subsection{Biomarkers}

High sensitivity CRP, IL-6, and sVCAM-1 were determined from plasma samples, which were obtained at each study visit and stored at $-80^{\circ} \mathrm{C}$. Assays were performed at the Clinical \& Epidemiologic Research Laboratory, Department of Laboratory Medicine at Children's Hospital in Boston as previously described (Garshick et al., 2018). 


\subsection{Assessment of indoor and ambient $\mathrm{PM}_{2.5}, \mathrm{BC}$, and $\mathrm{NO}_{2}$}

Weekly indoor fine particulate matter $\left(\mathrm{PM}_{2.5}\right)$ samples were collected using the Harvard School of Public Health (HSPH) Micro-environmental Automated Particle Sampler (APS) (Garshick et al., 2018; Tang et al., 2016) prior to each clinic visit in the main activity room of the house (excluding the kitchen). Daily ambient samples were collected at a Supersite located on the roof of the Harvard Medical School Library in downtown Boston (Huang et al., 2018; Kang et al., 2010). Indoor and ambient $\mathrm{PM}_{2.5}$ filters were weighed before and after sampling by an analytic balance (Micro-Gravimetric M5, Mettler Instruments Corp, Hightstown, NJ). Indoor black carbon (BC) concentrations were determined by measuring the blackness of the particles collected on the weekly filter using a smoke stain reflectometer (model EEL m43d, Diffusion System Ltd., United Kingdom). Ambient BC concentrations were measured by an aethalometer (Magee Scientific Company, model AE-16, Berkeley, CA) (Kang et al., 2010). Ambient nitrogen dioxide $\left(\mathrm{NO}_{2}\right)$ concentrations were the adjusted mean values from 3 U.S. EPA monitoring stations in Boston region. Indoor $\mathrm{NO}_{2}$ was collected using Ogawa passive sampling badges clipped to the micro-environmental particle samplers, and then extracted from the filters and analyzed by ion chromatography (Ruiz et al., 2010). Indoor samples were collected over a mean of 7.6 days; ambient daily $\mathrm{PM}_{2.5}, \mathrm{BC}$ and $\mathrm{NO}_{2}$ concentrations for each participant were averaged over the same dates as the indoor sample collection.

\subsection{Assessment of exposure to gamma radiation}

Ambient gamma activities-Ambient gross gamma count rate data (counts/minute, CPM) in Boston were obtained from the U.S. EPA's RadNet system, which is part of a national EPA background radiation monitoring network. Each monitoring station is equipped with a Total Suspended Particle (TSP) high volume air sampler for continuous measurement of gamma radiation emitted by TSP collected on a filter. The full gamma energy spectrum (range from 50 to $2000 \mathrm{keV}$ ) is measured hourly and sent to the National Air and Radiation Environmental Laboratory (NAREL). The gamma spectrum is characteristic of the gamma-emitting nuclides contained in the source. Details about the EPA airborne gamma spectrometry system have been published elsewhere (Cardarelli et al., 2010; EPA, 2005 and 2009). The data are reported in 9 different channels related to gamma energy wavelength bands. Data for gamma-1 activity are not reported by EPA due to the interference of the background radiation. In addition, we did not include gamma- 2 activity in this analysis due to substantial missing data (25.6\%). Therefore, in our analysis we used data for 7 channels, i.e., gamma-3 through gamma-9. Energy wavelength bands of these gamma activities are: $201-400 \mathrm{keV}$ for gamma-3, 401-600 keV for gamma-4, 601-800 keV for gamma-5, 801-1000 keV for gamma-6, 1001-1400 keV for gamma-7, 1401-1800 keV for gamma-8, and 1801-2200 keV for gamma-9. We constructed daily averages of ambient gamma activities based on the hourly data.

Ambient PM gamma activities-As the gamma spectrometers are not well-shielded, the directly measured RadNet gamma activities include background radiation from terrestrial and cosmic radiation that is relatively constant (Ramadhan and Abdullah, 2018). Therefore, in order to reflect changes in daily exposures to PM gamma radioactivity, daily RadNet measurements need to be corrected by subtracting estimates of background radiation (Vieira 
et al., 2019). As there is no standard method for correcting these measurements, we explored background radiation using the 7,21, 28, and 90 day moving-averages of gamma-3 through gamma-9 activity for each daily measurement. We then assessed the Pearson correlation between daily gamma data adjusted for background (reflecting fluctuations in PM-bound gamma activity) and daily central site $\mathrm{PM}_{2.5}$ measurements. Person correlations coefficients using different moving-averages to represent background are shown in Table S1 of the Supplementary Material. The best correlation $(\mathrm{p}<0.05)$ between the corrected daily gamma activities and daily ambient $\mathrm{PM}_{2.5}$ concentrations was found when subtracting the 21-day average. This finding suggests that the daily corrected gamma activities calculated using the 21-day average as background reflects daily changes in PM radioactivity. Our approach produces negative and positive values of PM gamma activities because the adjusted measurement is relative to background terrestrial and cosmic radiation. Figure S1 in the Supplementary Material shows the variability of the RadNet data plotted relative to the average 21-day background gamma radiation activities for gamma-3 to gamma-9. After we corrected the daily ambient PM gamma activities, we created moving averages for ambient PM gamma activities (gamma-3 to gamma-9) starting with the day of phlebotomy (day 0) to seven days before phlebotomy (day 7).

Indoor PM gamma activities-On average, in the COPD cohort, persons spent approximately 17 hours inside their homes daily (Garshick et al., 2018). Previous studies have used sulfur measured at a central site as a tracer of outdoor fine particles (Sarnat et al., 2002). This makes it possible to estimate the fraction of outdoor particles infiltrating indoors using the ratio of indoor to outdoor sulfur (Kang et al., 2010). In order to assess indoor exposures to ambient PM gamma activities, we assumed that the infiltration rate of PM carrying radionuclides emitting gamma radiation is similar to $\mathrm{PM}_{2.5}$. Therefore, the indoor exposure to ambient PM gamma activities was estimated by multiplying ambient PM gamma activities by indoor-outdoor sulfur ratio. Sulfur concentrations from the weekly indoor $\mathrm{PM}_{2.5}$ samples and from the daily Supersite samples (for outdoor measurement) were analysed using an $\mathrm{x}$-ray fluorescence spectrometer, and the Supersite concentrations were averaged over the same days as the indoor samples (Huang et al., 2018). When the indooroutdoor sulfur ratio is larger than 1.2, there may be an important indoor source and sulfur cannot be used as a tracer of outdoor particles (Huang et al., 2018). Therefore, we excluded observations with sulfur ratios greater than 1.2. We also constructed moving averages for indoor PM gamma activities from the day of phlebotomy (day 0 ) to seven days before phlebotomy (day 7).

\subsection{Covariates}

We considered covariates including meteorological parameters (i.e., temperature and relative humidity on the day of phlebotomy, participant demographics (i.e., age and race), health conditions (i.e., diabetes, heart disease, and recent cold or other respiratory illness in the last two weeks), season, body mass index (BMI), and blood draw time. Daily outdoor temperature at each participant's home was estimated using an exposure model based on satellite remote sensing, land use, and ground level temperature data (Kloog et al., 2014). Daily relative humidity was obtained from measurements at the Boston Logan International Airport weather station. Information on demographics and health conditions were obtained 
from questionnaires. BMI was calculated from weight and height obtained at each visit. Blood sampling time was recorded at each clinic visit. Seasons were classified using the month of the visit as the following: winter (December, January, February), spring (March, April, May), summer (June, July, August), or fall (September, October, November).

\subsection{Statistical methods}

We used linear mixed-effects models (using package "Ime4" in R) to examine the associations between each of the PM gamma activities and biomarkers of systemic inflammation for different exposure windows. We included a random intercept for each participant to capture the individual differences. Each biomarker was natural logtransformed to meet model assumptions. We performed the models both for ambient and indoor PM gamma activities. Results were expressed as percentage increases per interquartile range (IQR) of each gamma channel for each exposure window.

In order to consider the possible confounding by other pollutants, we also performed sensitivity analyses by adjusting the indoor and outdoor PM gamma activity models for the directly measured indoor weekly and corresponding ambient exposures, respectively, to BC, $\mathrm{PM}_{2.5}$, and $\mathrm{NO}_{2}$. The correlation between the weekly indoor and ambient PM gamma activities and the corresponding weekly indoor and ambient $\mathrm{PM}_{2.5}, \mathrm{BC}$, and $\mathrm{NO}_{2}$ was assessed. The validity of model assumptions was confirmed by examination of model residuals. All statistical analyses were performed using R (James et al., 2013). We consider the association as significant when $p<0.05$.

\section{Results}

\subsection{Subject Characteristics}

Characteristics of the 85 study participants and 263 clinic visits are presented in Table 1 . The analysis included 35 patients with 4 clinic visits, 31 with 3 clinic visits, 11 with 2 clinic visits, and 8 with 1 clinic visit (Figure S2 in the Supplementary Material). The median (25$75^{\text {th }}$ percentile) time between the first and last study visit was 312 (207-327) days. All participants were male and $89.4 \%$ were white. The average participant age was $72.7 \pm 8.6$ years old and $45 \%$ had a BMI $330 \mathrm{~kg} / \mathrm{m}^{2}$. About a quarter of participants reported diabetes, while about half reported heart disease.

Table 2 shows the descriptive information of the environmental data on the day of phlebotomy, including ambient and indoor exposures to PM gamma activities and other pollutants including $\mathrm{BC}, \mathrm{PM}_{2.5}$ and $\mathrm{NO}_{2}$, temperature and relative humidity, as well as season. About $21.7 \%$ of the visits occurred during the winter, $30.4 \%$ of the visits occurred during the spring, $28.1 \%$ occurred during the summer, and $19.8 \%$ occurred in the fall. Descriptive information of ambient and indoor PM gamma activities for different exposure windows were shown in Table S2 and S3 in the Supplementary Material.

The number of observations in our model was less than that of our previous study ( $\mathrm{n}=287$ ) (Garshick et al., 2018) as we excluded observations with missing gamma activities. The number of observations varied depending on the availability of daily gamma and sulfur data, with a maximum of 263 observations for ambient and up to 257 for the indoor exposures. 
Details of the number of the observations for ambient and indoor gamma activities with different exposure windows are shown in Table S2 and S3 in the Supplementary Material.

\subsection{Effects of PM gamma activities on biomarkers}

We assessed the associations between ambient and indoor PM gamma activities starting with the day of phlebotomy to moving averages through 7 days before phlebotomy. Percentage changes in IL-6, CRP, and sVCAM-1 per IQR PM gamma activities (gamma-3 through gamma-9) are shown in Figures 1-3.

Effects of ambient and indoor PM gamma on CRP were similar, and in general, there were stronger positive associations observed for longer exposure moving averages (Figure 1). As an example, for every IQR increase in ambient PM gamma averaged from phlebotomy day through previous 6 days, increases in CRP ranged from $8.75 \%$ (95\%CI: $-0.57,18.95$ ) to $14.8 \%$ (95\% CI: 4.5, 26.0) across the gamma channels. For every IQR increase in indoor PM gamma for the same moving average, CRP increased from $7.45 \%$ (95\%CI: $2.77,12.4)$ to $13.4 \%$ (95\% CI: 5.82, 21.4) across gamma channels.

For IL-6, there were also positive associations with stronger effect estimates for longer moving averages of ambient and indoor PM gamma activities (Figure 2). For exposure windows averaged from phlebotomy day through previous 6 days, the percentage increases per IQR ambient PM gamma activities were from 0.03\% (95\%CI: -6.37, 6.87) to $3.50 \%$ (95\%CI: $-3.15,10.61$ ), as shown in Figure 2(a). For indoor exposures for the same exposure period, the percentage increase ranged from $3.56 \%$ (95CI\%: $0.31,6.91)$ to $6.46 \%(1.33$, 11.85) as shown in Figure 2(b).

No consistent meaningful associations were found between PM gamma activities and sVCAM-1, either for ambient or indoor exposures (Figure 3).

Detailed values of percentage changes of CRP, IL-6 and sVCAM- 1 with per IQR increase in ambient or indoor PM gamma activities are presented in Table S4-S9 in the Supplementary Material.

\subsection{Effects of PM gamma activities on biomarkers adjusted for other pollutants}

We explored two-pollutant models that included ambient (central site) or indoor BC, $\mathrm{PM}_{2.5}$, and $\mathrm{NO}_{2}$ as potential confounders of associations with ambient and indoor gamma activities. The results of two-pollutant models were similar to the results for unadjusted models as shown in Figure S3-S11 in the Supplementary Material.

As shown in Table S10 in Supplementary Material, there was no meaningful correlation between indoor PM gamma activities and the corresponding indoor or ambient $\mathrm{BC}, \mathrm{PM}_{2.5}$ and $\mathrm{NO}_{2}$ concentrations ( $p$-value of Pearson correlation were mostly larger than 0.05 ). Nearly all the correlation coefficients between ambient PM gamma activities and the above pollutants all were less than 0.25 , indicating at most a weak association and no collinearity between PM gamma activities and these pollutants. 
When adjusting for BC, increases in CRP ranged from $8.73 \%$ (95\%CI: $-1.17,19.6)$ to 14.3\% (95\% CI: 4.00, 25.6) per IQR increase in ambient PM gamma activities averaged from phlebotomy day through previous 6 days and from $6.96 \%$ (95\%CI: $2.10,12.1)$ to $12.9 \%$ (95\%CI: 5.11,21.2) per IQR increases in indoor exposures averaged over the previous six days. When adjusting for $\mathrm{PM}_{2.5}$ or $\mathrm{NO}_{2}$, effects of $\mathrm{PM}$ gamma activities on CRP were also similar with unadjusted models as shown in Figure S6 and S9, respectively.

When adjusting for BC, levels of IL-6 increased from $0.10 \%$ (95\%CI: $-6.53,6.77)$ to 3.30 (95\% CI: $-3.47,10.54)$ for every IQR increase in ambient PM gamma activities averaged from phlebotomy day through previous 6 days, and from $3.83 \%$ (95\%CI: $0.46,7.32$ ) to $6.83 \%$ (95\%CI: $1.54,12.41$ ) with indoor exposures. When adjusting for $\mathrm{PM}_{2.5}$ or $\mathrm{NO}_{2}$, effect of PM gamma activities on IL-6 were also similar to unadjusted models (Figure S7 and S10), though the effects of indoor PM gamma activities had wider confidence intervals when adjusting for $\mathrm{PM}_{2.5}$.

No meaningful associations were found between PM gamma activities and sVCAM-1 for all the two-pollutant models (Figures S5, S8, and S11).

\section{Discussion}

We investigated the effects of ambient and indoor PM gamma activities with moving averages up to 7 days before phlebotomy on biomarkers of systemic inflammation (i.e., IL-6, CRP) and endothelial activation (i.e., sVCAM-1). There were positive associations with ambient and indoor PM gamma activities with IL-6 and CRP, with stronger effects for CRP; however, there were no consistent associations with SVCAM-1. We conducted a sensitivity analysis to consider possible confounding by indoor or central site $\mathrm{BC}, \mathrm{PM}_{2.5}$ or $\mathrm{NO}_{2}$ exposures. The association between ambient and indoor PM gamma activities and each biomarker were similar with adjusted or unadjusted models, making it unlikely the findings could be attributable to other pollution-related components. Our findings suggest that PM with attached radionuclides may contribute to adverse health effects in COPD patients by promoting systemic inflammation, independently of $\mathrm{BC}, \mathrm{PM}_{2.5}$ or $\mathrm{NO}_{2}$.

The relationships between ambient PM gamma and CRP were similar to those of indoor PM gamma and CRP. Although we found positive associations between indoor and ambient gamma activities and IL-6, effects of indoor PM gamma activities were larger and more precise. As COPD patients spend most of their time indoors, exposures to indoor PM gamma activities (representing the infiltration of outdoor PM gamma activities) may be more relevant for health effects. Although PM gamma activities influenced both CRP and IL-6, the effects on CRP were stronger and more consistent. In our previous study in this cohort (Garshick et al., 2018), BC also had stronger effects on CRP as compared to IL-6. This is possibly due to different half-lives for the two biomarkers. CRP has a longer plasma half-life (19 h) compared with IL-6 (less than 6 h) (Pepys, 2003; Ridker et al., 2000). Therefore, it is possible that CRP could remain elevated longer in response to exposure to PM gamma activities. 
Our results indicated that PM radioactivity at current ambient levels may promote systemic inflammation in COPD patients. In human lung fibroblasts, there is support for a low dose of a-radiation inducing production of interleukin- 8 as an indicator of an inflammatory response (Narayanan et al., 1999). Human pulmonary epithelial cells exposed to a-radiation have also demonstrated up-regulation of gene pathways associated with inflammatory and respiratory diseases (Chauhan et al., 2012). Mice exposed to low doses of gamma radiation also developed evidence of chronic pulmonary inflammation (Christofidou-Solomidou et al., 2015). As evidence of a systemic effect of PM radioactivity in persons without COPD, in members of the Framingham Heart Study, Li et al. (2018) found that exposure to higher PM radioactivity was associated with higher circulating levels of IL-6 and P-selectin. Another recent study also found higher PM radioactivity was associated with an elevation in both diastolic and systolic blood pressure (Nyhan et al., 2018). Blomberg et al. (2018) recently found that indoor radon exposures (a source of ionizing radiation exposures), through interactions with PM, were associated with total, cardiovascular, and respiratory mortality risk based on 112 cities in the U.S. In addition to the alpha and beta emissions that accompany the decay of environmental radionucleides, gamma radiation is also frequently emitted (Stacey, 2007), indicating that PM gamma activities may be a surrogate for total radioactivity emitted from PM. Vieira et al. (2019) in our research group investigated effects of PM gamma activities on pulmonary function in the same COPD cohort as in this report and found indoor and ambient PM gamma activities were associated with decreases in FEV 1 and FVC. These findings support the effects of PM associated radioactivity on inflammatory biomarkers and the potential effects of PM associated radioactivity at low levels on the health of COPD patients.

The present study also has some limitations. Specifically, most participants were Veterans with COPD receiving care at VA Boston, most of whom were Caucasian males, which may limit the generalizability of our findings if there are plausible differences in biological mechanisms in different populations. Our study only included participants who were able to travel to VA Boston for a study visit and were able to receive and ship samplers back to us. Therefore, we were unable to include individuals with very severe COPD who may have greater systemic response to PM gamma activities, so these results may not be representative of effects in all COPD patients. Since we did not have any direct measurement of PM radioactivity, we calculated daily exposures to PM gamma activities by subtracting estimated ambient background exposures from RadNet data, an approach that would have reduced our ability to detect an effect as daily PM gamma activities were estimated. Finally, we used the indoor/outdoor sulfur ratio to estimate indoor exposures without considering the contribution of indoor sources of radiation since indoor measurements are not available, potentially underestimating the full burden of indoor exposures.

This study has many strengths. To the best of our knowledge, this is the first study to investigate relationships between exposures to PM gamma activities and systemic inflammation and endothelial dysfunction. Additionally, the study assessed indoor exposures to PM gamma activities where the COPD patients spend most of their time, and all participants have well documented COPD as confirmed by both their COPD diagnosis from medical records and spirometry measures. 


\section{Conclusion}

This study has implications for understanding effects of low-level radiation associated with PM on systemic effects that have not previously been appreciated. We observed positive associations between ambient and indoor PM gamma activities as surrogates of PM radioactivity and biomarkers of systemic inflammation in COPD patients. Our finding suggests that PM with attached radionuclides may contribute to adverse health effects.

\section{Supplementary Material}

Refer to Web version on PubMed Central for supplementary material.

\section{Acknowledgements:}

This publication was funded by the National Institute of Health (NIH) grants (P01-ES009825 and R01-ES019853), the National Institute of Environmental Health Sciences (NIEHS) (P30-ES000002), and was conducted with resources and the use of facilities at the VA Boston Healthcare System. The contents do not reflect the position of the Department of Veterans Affairs or the United States Government. This publication was also made possible by USEPA grant (RD-835872-01) through the Harvard University USEPA sponsored Air, Climate \& Environment (ACE) Centre. The contents of the study are solely the responsibility of the grantee and do not necessarily represent the official views of the USEPA. Further, USEPA does not endorse the purchase of any commercial products or services mentioned in the publication. We also thank Mike Wolfson for assisting with manuscript revisions.

\section{References}

Agusti AG. 2005 Systemic effects of chronic obstructive pulmonary disease. Proc Am Thorac Soc 2(4): 367-370. [PubMed: 16267364]

Agusti AG, Noguera A, Sauleda J, Sala E, Pons J, Busquets X. 2003 Systemic effects of chronic obstructive pulmonary disease. Eur Respir J 21(2): 347-360. [PubMed: 12608452]

Agusti AG, Edwards LD, Rennard SI, MacNee W, Tal-Singer R, Miller BE, et al. 2012 Persistent systemic inflammation is associated with poor clinical outcomes in COPD: a novel phenotype. PLoS One 7(5): e37483. [PubMed: 22624038]

Blomberg AJ, Coull BA, Jhun I, Vieira CLZ, Zanobetti A, Garshick E, et al. 2018 Effect modification of ambient particle mortality by radon: a time series analysis in 108 U.S. cities. J Air Waste Manag Assoc. doi: 10.1080/10962247.2018.1523071.

Cardarelli J, Thomas M, Curry T. 2018 Environmental Protection Agency (EPA) airborne gamma spectrometry system for environmental and emergency response surveys. Proc SPIE 2010; 7812(1): 179-184.

Chauhan V, Howland M, Mendenhall A, O'Hara S, Stocki TJ, McMamee JP, et al. 2012 Effects of alpha particle radiation on gene expression in human pulmonary epithelial cells. Int J Hyg Environ Health 215(5): 522-535. [PubMed: 22608759]

Christofidou-Solomidou M, Pietrofesa RA, Arguiri E, Schweitzer KS, Berdyshev EV, McCarthy M, et al. 2015 Space radiation-associated lung injury in a murine model. Am J Physiol Lung Cell Mol Physiol. 308(5): L416-28. [PubMed: 25526737]

Croft JB, Wheaton AG, Liu Y, Xu F, Lu H, Matthews KA, et al. 2018 Urban-Rural County and State Differences in Chronic Obstructive Pulmonary Disease — United States, 2015. MMWR Morb Mortal Wkly Rep. 67(7): 205-211. [PubMed: 29470455]

Environmental Protection Agency (EPA). 1972 Natural radiation exposure in the United States.

Environmental Protection Agency (EPA). 2005 Expansion and Upgrade of the RadNet Air Monitoring Network. U.S. EPA.

Environmental Protection Agency (EPA). 2009 Radiological Laboratory Sample Analysis Guide for Incidents of National Significance - Radionuclides in Air. U.S. EPA. 
Foray N, Randrianarison V, Marot D, Perricaudet M, Lenoir G, Feunteun J. 1999 Gamma-rays-induced death of human cells carrying mutations of BRCA1 or BRCA2. Oncogene 18(51): 7334-7342. [PubMed: 10602489]

Garshick E. 2014 Effects of short- and long-term exposures to ambient air pollution on COPD. Eur Respir J 44(3): 558-561. [PubMed: 25176946]

Garshick E, Grady ST, Hart JE, Coull BA, Schwartz J, Laden F, et al. 2018 Indoor Black Carbon and Biomarkers of Systemic Inflammation and Endothelial Activation in COPD Patients. Environ Res 165: 358-364. [PubMed: 29783085]

Heinrich J, Schikowski T. 2018 COPD Patients as Vulnerable Subpopulation for Exposure to Ambient Air Pollution. Curr. Environ Health Rep 5(1): 70-76. [PubMed: 29383658]

Henner WD, Grunberg SM, Haseltine WA. 1982 Sites and structure of gamma radiation-induced DNA strand breaks. J Biol Chem 257(19): 11750-11754. [PubMed: 7118909]

Huang SD, Lawrence J, Kang CM, Li J, Martins M, Vokonas P, et al. 2018 Road proximity influences indoor exposures to ambient fine particle mass and components. Environ Pollut 243(Pt B): 978987. [PubMed: 30248605]

James G, Witten D, Hastie T, Tibshirani R. 2013 An introduction to statistical learning with applications in R. Springer New York.

Jiang XQ, Mei XD, Feng D. 2016 Air pollution and chronic airway diseases: what should people know and do? J Thorac Dis 8(1): E31-E40. [PubMed: 26904251]

Kang CM, Koutrakis P, Suh HH. 2010 Hourly measurements of fine particulate sulfate and carbon aerosols at the Harvard-U.S. Environmental Protection Agency Supersite in Boston. J Air Waste Manag Assoc 60(11): 1327-1334. [PubMed: 21141426]

Karam PA. 2004 Radiological Terrorism. Hum Ecol Risk Assess 11(3): 501-523.

Kloog I, Nordio F, Coull BA, Schwartz J. 2014 Predicting spatiotemporal mean air temperature using MODIS satellite surface temperature measurements across the Northeastern USA. Remote Sens Environ 150, 132-139.

Li W, Nyhan MM, Wiker EH, Vieira CLZ, Lin HH, Schwartz JD, et al. 2018 Recent exposure to particle radioactivity and biomarkers of oxidative stress and inflammation: The Framingham Heart Study. Environ Int 121, 1210-1216. [PubMed: 30376999]

Mackay AJ, Patel ARC, Singh R, Sapsford R, Compton C, Prasad N, et al. 2016 Increased Systemic Inflammation, as Measured by Absolute Levels and Change in IL-6, at Exacerbation Onset Predicts Clinical Non-Recovery at 35 Days. Am J Resp Crit Care Med 193: A1023.

Marsh JW, Bailey MR. 2013 A review of lung-to-blood absorption rates for radon progeny. Radiat Prot Dosimetry 157(4): 499-514. [PubMed: 23887272]

Mishra KP. 2004 Cell membrane oxidative damage induced by gamma-radiation and apoptotic sensitivity. J Environ Pathol Toxicol Oncol. 23(1): 61-66. [PubMed: 14994996]

Mohamed A, El-hady MA, Moustafa M, Yuness M. 2014 Deposition pattern of inhaled radon progeny size distribution in human lung. J Radiat. Res Appl Sci 7(3): 333-337.

Morrison DF. 2005 Multivariate analysis of variance. Encycl Biostatist dio: 10.1002/0470011815.b2a13045.

Narayanan PK, LaRue KE, Goodwin EH, Lehnert BE. 1999 Alpha particles induce the production of interleukin-8 by human cells. Radiat Res 152(1): 57-63. [PubMed: 10381841]

Nyhan MM, Coull BA, Blomberg AJ, Vieira CLZ, Garshick E, Aba A, et al. 2018 Associations Between Ambient Particle Radioactivity and Blood Pressure: The NAS (Normative Aging Study). J Am Heart Assoc doi: 10.1161/JAHA.117.008245.

Pepys MB, Hirschfield GM. 2003 C-reactive protein: a critical update. J Clin Invest 111(12): 18051812. [PubMed: 12813013]

Polverino F, Celli BR, Owen CA. 2018 COPD as an endothelial disorder: endothelial injury linking lesions in the lungs and other organs? Pulm Circ 8(1); 2045894018758528.

Porstendörfer J. 1994 Properties and behaviour of radon and thoron and their decay products in the air. J Aerosol Sci 25(2): 219-263.

Porstendörfer J. 2001 Physical parameters and dose factors of the radon and thoron decay products. Radiat Prot Dosimetry 94(4): 365-973. [PubMed: 11499441] 
Ramadhan RA, Abdullah KMS. 2018 Background reduction by $\mathrm{Cu} / \mathrm{Pb}$ shielding and efficiency study of NaI (TI) detector. Nucl Eng Technol 50 (3): 462-469.

Ridker PM, Hennekens CH, Buring JE, Rifai N. 2000 C-reactive protein and other markers of inflammation in the prediction of cardiovascular disease in women. N Engl J Med. 342(12): 836843. [PubMed: 10733371]

Ruiz PA, Toro C, Cáceres J, López G, Oyola P, Koutrakis P. 2000 Effect of Gas and Kerosene Space Heaters on Indoor Air Quality: A Study in Homes of Santiago, Chile. J Air Waste Manage 60(1): 98-108.

Sarnat J, Long CM, Koutrakis P. 2002 Using sulfur as a tracer of outdoor fine particulate matter. Environ Sci Technol 36(24): 5305-5314. [PubMed: 12521154]

Shahbazi-Gahrouei D, Gholami M, Setayandeh S. 2013 A review on natural background radiation. Adv Biomed Res 2(3): 65. [PubMed: 24223380]

Shaw JG, Vaughan A, Dent AG, O'Hare PE, Goh F, Bowman RV, et al. 2014 Biomarkers of progression of chronic obstructive pulmonary disease (COPD). J Thorac Dis 6(11): 1532-1547. [PubMed: 25478195]

Stacey WM, 2007 Introductory nuclear physics, 2nd, completely revised and enlarged edition. WileyVCH, Verlag GmbH \& Co. KgaA, Weinheim.

Su B, Liu TS, Fan HJ, Chen F, Ding H, Wu ZW, et al. 2016 Inflammatory markers and the risk of chronic obstructive pulmonary disease: a systematic review and meta-analysis. PLoS One 11(4): e0150586. [PubMed: 27104349]

Tang CH, Garshick E, Grady S, Coull B, Schwartz J, Koutrakis P, 2017 Development of SatelliteBased Emission Inventories and Indoor Exposure Prediction Models for PM2.5. J Expo Sci Environ Epidemiol dio: 10.1038/jes.2017.11.

Vieira CLZ, Koutrakis P, Huang SD, Grady S, Hart JE, Coull BA, et al. 2019 Short-term effects of particle gamma activity on lung function in a chronic obstructive pulmonary disease cohort in Eastern Massachusetts, USA. Environ Res 175: 211-227.

Wheaton AG, Cunningham TJ, Ford ES, Croft JB, Centers for Disease Control and Prevention (CDC). 2015 Employment and Activity Limitations Among Adults with Chronic Obstructive Pulmonary Disease - United States, 2013. MMWR Morb Mortal Wkly Rep 64(11): 289-295. [PubMed: 25811677] 


\section{Highlights}

1. A novel study about systemic effects of PM radioactivity in COPD patients.

2. We assessed PM gamma activities indoor, where patients spend most their time.

3. We found positive associations between PM gamma activities with CRP and IL-6.

4. Our results indicated toxicity of current ambient radiation associated with PM. 


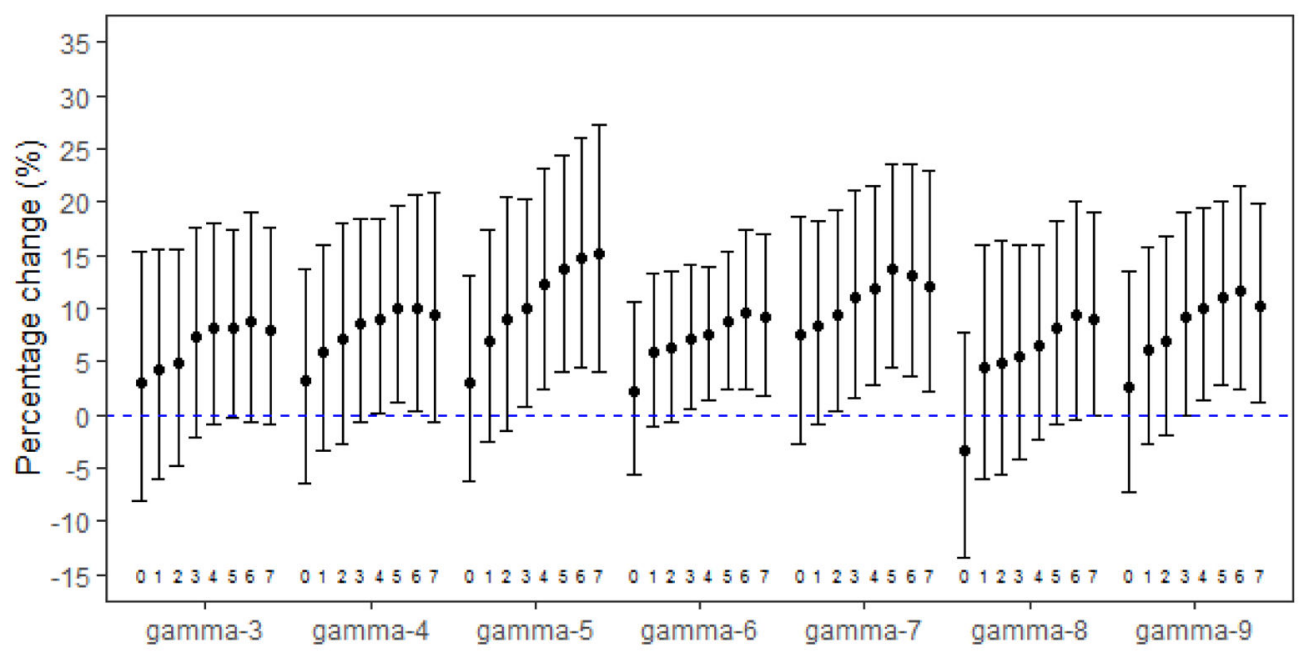

(a) Effects of ambient PM gamma activities on CRP

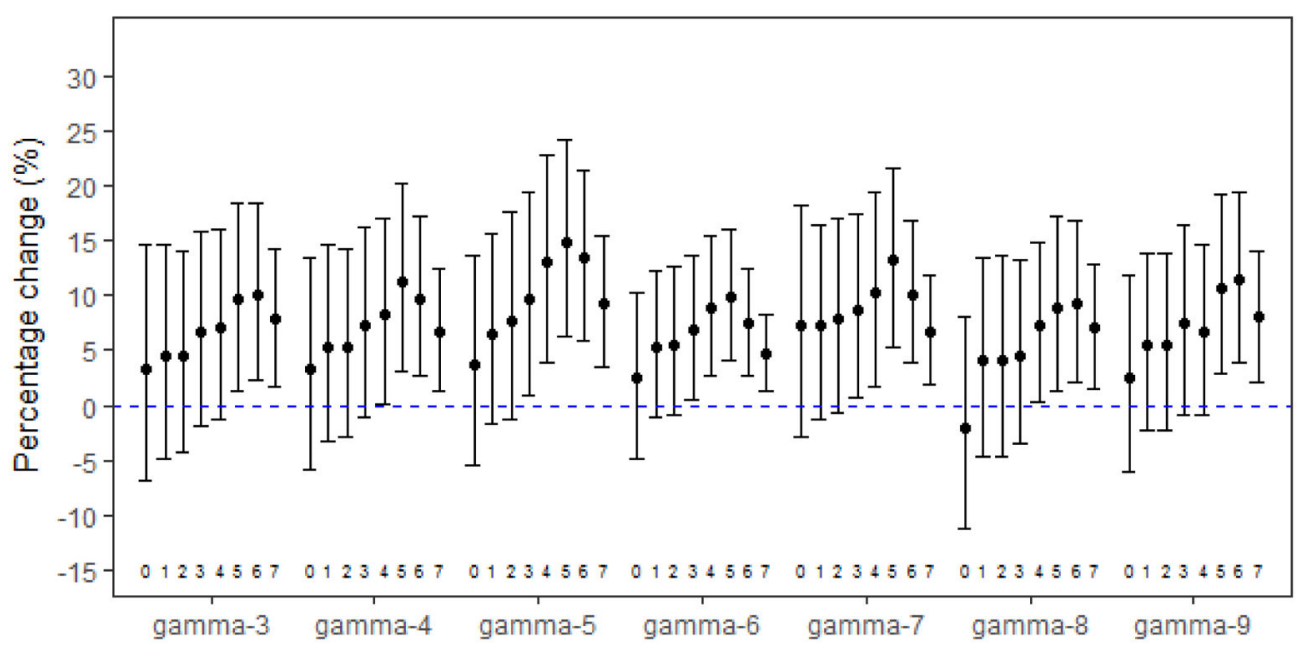

(b) Effects of indoor PM gamma activities on CRP

Figure 1.

Percentage changes in CRP per IQR increase in exposures to ambient (a) and indoor (b) PM gamma channels 3 through 9 for daily moving averages starting with the day of phlebotomy (day 0 ) through 7 days before phlebotomy (day 7), among 85 individuals with COPD. 


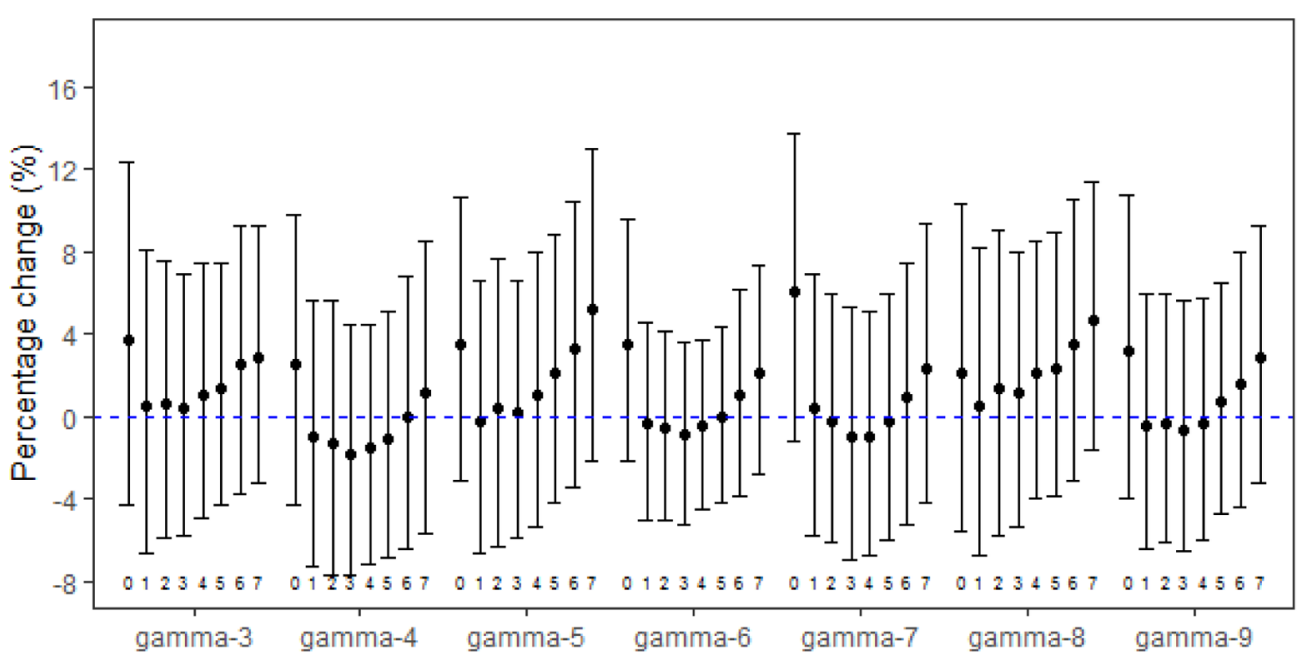

(a) Effects of ambient PM gamma activities on IL-6

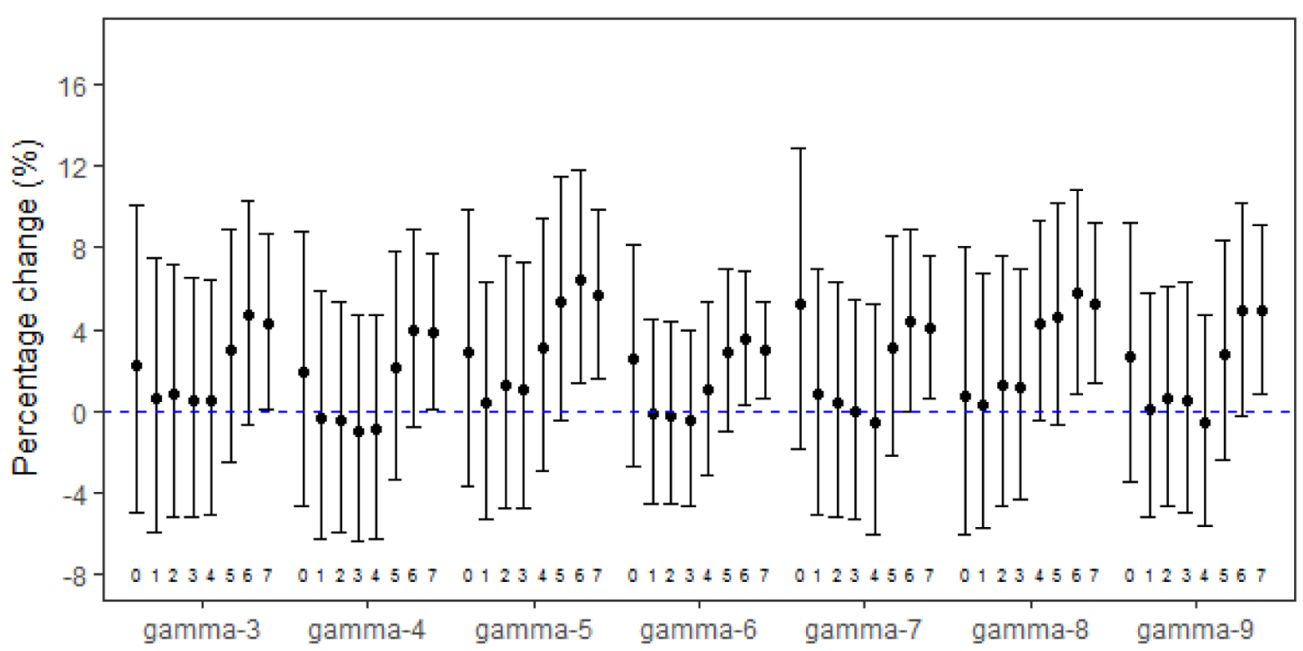

(b) Effects of indoor PM gamma activities on IL-6

Figure 2.

Percentage changes in IL-6 per IQR increase in exposures to ambient (a) and indoor (b) PM gamma channels 3 through 9 for daily moving averages starting with the day of phlebotomy (day 0 ) through 7 days before phlebotomy (day 7), among 85 individuals with COPD. 


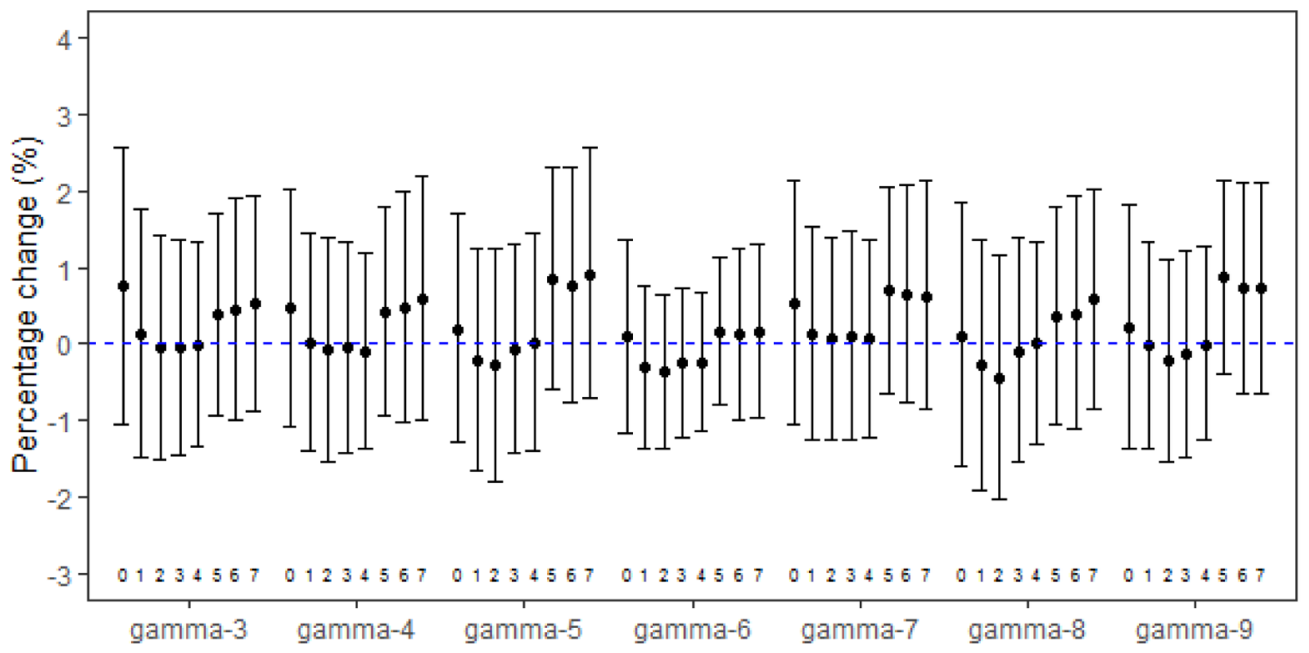

(a) Effects of ambient PM gamma activities on SVCAM-1

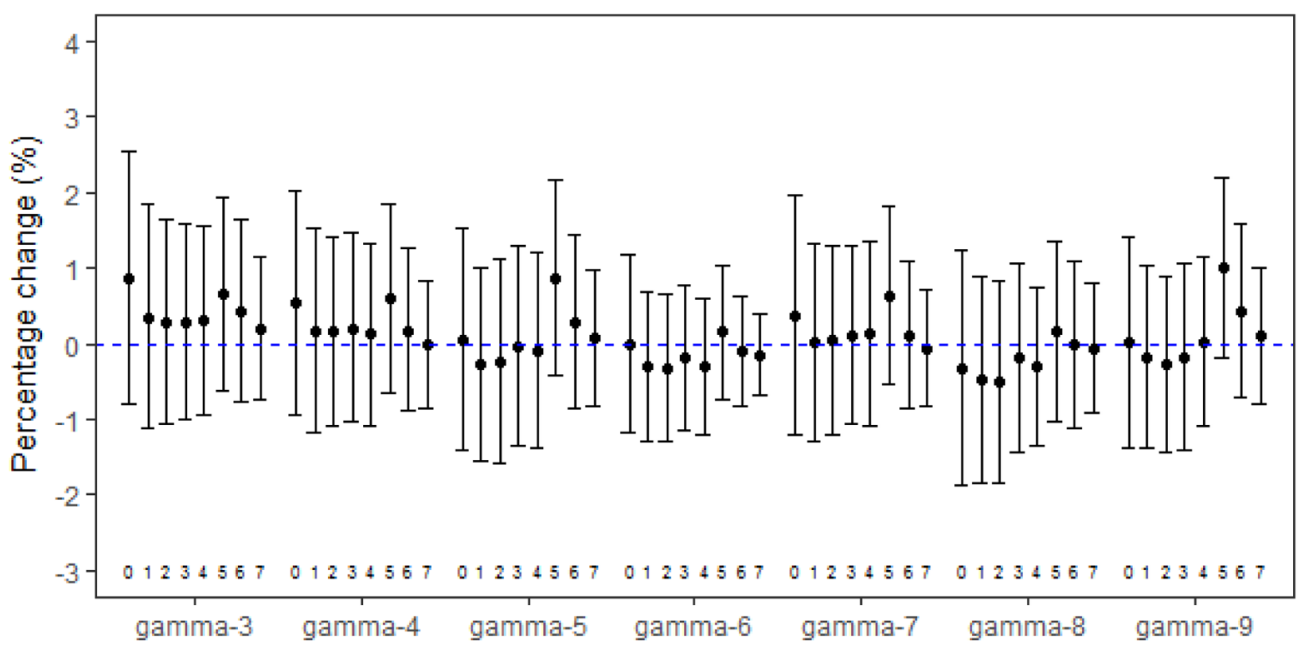

(b) Effects of indoor PM gamma activities on SVCAM-1

Figure 3.

Percentage changes in SVCAM-1 per IQR increase in exposures to ambient (a) and indoor (b) PM gamma channels 3 through 9 for daily moving averages starting with the day of phlebotomy (day 0) through 7 days before phlebotomy (day 7), among 85 individuals with COPD. 
Table 1.

Descriptive information of 85 COPD patients collected over 1 to 4 clinic visits $(n=263)$

\begin{tabular}{|c|c|c|c|}
\hline \multicolumn{4}{|c|}{ (a) 85 participants at study entry } \\
\hline \multicolumn{2}{|l|}{ Variables } & Mean (SD) & Range \\
\hline \multicolumn{2}{|l|}{ Age (yrs) } & $72.7(8.6)$ & $46.7-90.7$ \\
\hline \multicolumn{2}{|l|}{ BMI $\left(\mathrm{kg} / \mathrm{m}^{2}\right)$} & $30.0(5.6)$ & $18.8-50.8$ \\
\hline & & \multicolumn{2}{|l|}{$\mathbf{N}(\%)$} \\
\hline \multirow[t]{2}{*}{ Race } & White & \multicolumn{2}{|l|}{$76(89.4 \%)$} \\
\hline & Non-white & \multicolumn{2}{|l|}{$9(10.6 \%)$} \\
\hline \multirow[t]{2}{*}{ Diabetes } & Yes & \multicolumn{2}{|l|}{$21(25.1 \%)$} \\
\hline & No & \multicolumn{2}{|l|}{$64(74.9 \%)$} \\
\hline \multirow[t]{2}{*}{ Heart disease } & Yes & \multicolumn{2}{|l|}{$41(48.2 \%)$} \\
\hline & No & \multicolumn{2}{|l|}{$44(51.8 \%)$} \\
\hline \multicolumn{4}{|c|}{ (b) Biomarkers for 263 observations } \\
\hline \multicolumn{2}{|l|}{ Biomarker } & Median $\left(25-75^{\text {th }}\right.$ percentile $)$ & Range \\
\hline \multicolumn{2}{|l|}{ IL-6 (pg/mL) } & $3.1(2.1-5.4)$ & $0.5-49.9$ \\
\hline \multicolumn{2}{|l|}{$\mathrm{CRP}(\mathrm{mg} / \mathrm{L})$} & $2.8(1.3-6.2)$ & $0.2-46.9$ \\
\hline \multicolumn{2}{|c|}{ sVCAM-1 (ng/mL) } & $895.8(749.5-1069.8)$ & $371.1-2152.0$ \\
\hline
\end{tabular}


Table 2.

Ambient and indoor PM gamma activities, $\mathrm{BC}, \mathrm{PM}_{2.5}$ and $\mathrm{NO}_{2}$, meteorology, and season of assessment in 85 COPD patients ( $\mathrm{n}=263$ measurements).

\begin{tabular}{|c|c|c|}
\hline Variables & Median $\left(25,75^{\text {th }}\right.$ percentile $)$ & Range \\
\hline Temperature $\left({ }^{\circ} \mathrm{C}\right)$ & $12.0(3.8,19.2)$ & $-12.2 \sim 28.0$ \\
\hline Relative humidity (\%) & $65.1(52.5,79.0)$ & $30.7 \sim 97.0$ \\
\hline Ambient weekly BC concentration $\left(\mu \mathrm{g} / \mathrm{m}^{3}\right)$ & $0.54(0.41,0.78)$ & $0.27 \sim 1.41$ \\
\hline Ambient weekly $\mathbf{P M}_{2.5}$ concentration $\left(\mu \mathrm{g} / \mathrm{m}^{3}\right)$ & $5.93(4.99,7.94)$ & $3.38 \sim 13.4$ \\
\hline Ambient weekly $\mathrm{NO}_{2}$ concentration $\left(10^{-3} \mu \mathrm{g} / \mathrm{m}^{3}\right)$ & $25.9(21.2,30.1)$ & $14.5 \sim 42.3$ \\
\hline Ambient daily PM gamma-3 (CPM) & $4.77(-35.6,54.1)$ & $-224 \sim 270$ \\
\hline Ambient daily PM gamma-4 (CPM) & $-0.24(-6.00,9.13)$ & $-70.10 \sim 48.12$ \\
\hline Ambient daily PM gamma-5 (CPM) & $0.96(-4.69,6.70)$ & $-47.30 \sim 36.50$ \\
\hline Ambient daily PM gamma-6 (CPM) & $-0.05(-1.60,2.81)$ & $-30.09 \sim 13.91$ \\
\hline Ambient daily PM gamma-7 (CPM) & $0.61(-2.85,4.95)$ & $-35.1 \sim 20.4$ \\
\hline Ambient daily PM gamma-8 (CPM) & $0.42(-3.22,4.04)$ & $-25.2 \sim 14.1$ \\
\hline Ambient daily PM gamma-9 (CPM) & $0.02(-0.53,0.65)$ & $-3.78 \sim 3.81$ \\
\hline Indoor weekly BC concentration $\left(\mu \mathrm{g} / \mathbf{m}^{3}\right)$ & $0.18(0.09,0.30)$ & $-0.42-1.39$ \\
\hline Indoor weekly $\mathrm{PM}_{2.5}$ concentration $\left(\mu \mathrm{g} / \mathrm{m}^{3}\right)$ & $6.79(4.79,10.40)$ & $0.26-45.9$ \\
\hline Indoor weekly $\mathrm{NO}_{2}$ concentration $\left(10^{-3} \mu \mathrm{g} / \mathrm{m}^{3}\right)$ & $17.2(8.23,20.9)$ & $1.09 \sim 111.9$ \\
\hline Indoor daily PM gamma-3 (CPM) & $1.53(-25.9,37.0)$ & $-148 \sim 212$ \\
\hline Indoor daily PM gamma-4 (CPM) & $-0.01(-4.5,6.30)$ & $-40.8 \sim 44.3$ \\
\hline Indoor daily PM gamma-5 (CPM) & $0.50(-3.8,4.17)$ & $-29.0 \sim 34.2$ \\
\hline Indoor daily PM gamma-6 (CPM) & $0.00(-1.16,1.67)$ & $-17.5 \sim 15.9$ \\
\hline Indoor daily PM gamma-7 (CPM) & $0.42(-1.94,2.98)$ & $-20.4 \sim 20 \cdot 6$ \\
\hline Indoor daily PM gamma-8 (CPM) & $0.24(-2.36,2.61)$ & $-14.9 \sim 16.2$ \\
\hline \multirow[t]{2}{*}{ Indoor daily PM gamma-9 (CPM) } & $0.01(-0.32,0.44)$ & $-2.90 \sim 2.39$ \\
\hline & \multicolumn{2}{|l|}{$\mathbf{N}(\%)$} \\
\hline \multirow[t]{4}{*}{ Season } & Winter & $57(21.7 \%)$ \\
\hline & Spring & $80(30.4 \%)$ \\
\hline & Summer & $74(28.1 \%)$ \\
\hline & Fall & $52(19.8 \%)$ \\
\hline
\end{tabular}

